\title{
The value of error in complex times
}

The most recent editorial in this Journal ${ }^{1}$ discussed, in part, the impact of fires on the environment and on the research collections at the University of Cape Town. As we finalise this issue, it is again a time of fires in South Africa - some literal, in the context of violence following the arrest of the former State President, and others metaphorical, in the context of the deadly third wave of COVID-19. At such difficult times, there is probably no correct way to act or even to comment editorially - we do not have the solutions for all the huge challenges the country faces. It would be easier, perhaps, to ignore the country's experiences of violence and pandemic and to focus on other matters in an editorial, but this silence is in itself a political choice. There is no way out for privileged people having to take some responsibility for the privileged voice that we have, especially in times like these. This is the case even if, by the time this editorial is read, other issues have come to seem more prominent than the current ones.

How do we explain, in a helpful way, what is happening in South Africa and more broadly at present? There are so many possible levels of explanation. We can start at a micro-level, talking about what is happening in the brains of people who perpetrate violence. We can point out the impact of years of assault on some of those brains through under-nutrition, impoverished social circumstances, and the impact of trauma and substances. We can point to the literature on the strong relationship between social inequality and a range of poor social outcomes. We can take an historical view of the present, noting the impact of past and enduring injustice on current behaviour. We can look to the injustices of colonial and postcolonial history and to the increasing evidence of the deleterious effects of a range of forms of social exclusion and occupational deprivation. We can place this all in the context of species evolution, and beyond. All of these analyses have potential to shed light on our world; none is complete. As one of Africa's greatest writers, Chimamanda Ngozi Adichie, said in her TED talk dealing with issues of identity in literature (amongst other things), we need to consider 'the danger of a single story'.

Especially now, scientists, and especially social scientists, may be called upon, and may wish, to offer words of authority and decision - to provide the illusory comfort of a 'single story'. We know, however, that science is not about certainty but about debate, and about changing our minds as the evidence changes. It is never about having a single template into which everything can fit neatly. If we have such a template, then we never have to collect data again, as we know what the answer will always be.

Part of how we as scientists try to deal with multiplicity and the complexity of the real world is through multidisciplinarity - something very much to be celebrated, as we have suggested in this Journal before ${ }^{2}$, and, indeed, at the heart of what we do and believe we should do. But there are challenges. In response to the most recent editorial ${ }^{1}$, we were contacted by a conservation biologist who was concerned that it could be the view of the South African Journal of Science that fire is always a bad thing in relation to fynbos. As our interlocutor pointed out (and I did not make clear in the editorial), fire is in fact essential to the regeneration of Cape fynbos and renosterveld. The problem is the interface between humans and nature - there are issues here of poor management of invasive species, for example.

This issue, though, links to broader concerns about error, especially in an interdisciplinary journal where the Editor-in-Chief is not on top of all the sciences represented. We deal with this issue primarily, of course by having Associate Editors who are subject experts; these Associate Editors generally appoint reviewers as familiar as possible with the specific areas researched by authors.

But it is in the nature of science that nobody can know everything about any subject, and that mistakes and errors are often what drives fields forward - some theorists talk of errors as leading edges for new growth. Good scientists should be able to make mistakes, and to change their minds as new evidence emerges. It is part of the function of a journal like this one, as we have suggested before ${ }^{2}$, to expose readers to new ideas and to a multiplicity of perspectives. In practice, this important challenge forces us to think much more carefully, not just about views we may have and values we may hold, but about the strengths and weaknesses of our methods and the quality of our argumentation. For our authors, who come from a range of disciplines across the sciences (as broadly conceived of), and beyond, there is an extra burden which is often not carried when we write in discipline-specific journals. Our authors at their best make their methods and their argumentation accessible to people without discipline-specific skills and background knowledge. There is nothing more challenging or educational for a subject expert to make that expertise accessible to non-experts (in line with the old adage that the best way to learn is to teach); our authors have to address this challenge. There are issues at stake here not only of good science but also of good science communication. Multidisciplinarity is not about silos of knowledge where each group owns a territory; it is about the opportunities and risks of crossing boundaries. This takes time, commitment, and, indeed, courage.

As we confront the current, ongoing, and future challenges of our country, our continent, and our world, we thank our contributors for all they are already doing to take forward the agenda of the Journal - our vision remains 'To publish and promote the widest diversity of excellent South African research for the local and global academic community and inform policymakers and the public'. At times like these, it is clear that to reach this complex and multifaceted vision is easier said than done. Making mistakes and talking past one another is part of the process; to be part of enduring solutions we have to accept, and embrace error. The potential of what we have to offer lies not in easy pontification but in the constant recognition of, and struggle with, our limitations.

\section{References}

1. Swartz L. Information, loss, and the complex work of reclamation. S Afr J Sci. 2021;117(5/6), Art. \#11164. https://doi.org/10.17159/sajs.2021/11164

2. Carruthers J. Celebrating multidisciplinarity. S Afr J Sci. 2021;117(1/2), Art \#9391. https://doi.org/10.17159/sajs.2021/9391 